\title{
Agôn
}

Revue des arts de la scène

Critiques | Saison 2016-2017

\section{Avignon, 12 juillet : Hypothèse sur la télé \& le théâtre}

\section{Caroline Châtelet}

\section{(2) OpenEdition}

Journals

Édition électronique

URL : http://journals.openedition.org/agon/4033

DOI : $10.4000 /$ agon.4033

ISSN : 1961-8581

\section{Éditeur}

Association Agôn

Référence électronique

Caroline Châtelet, «Avignon, 12 juillet : Hypothèse sur la télé \& le théâtre », Agôn [En ligne], Critiques, mis en ligne le 12 juillet 2017, consulté le 15 septembre 2020. URL : http://journals.openedition.org/ agon/4033

Ce document a été généré automatiquement le 15 septembre 2020

Association Agôn et les auteurs des articles 


\title{
Avignon, 12 juillet : Hypothèse sur la télé \& le théâtre
}

\author{
Caroline Châtelet
}

1 En passant, fissa, une hypothèse, peut-être bien peu charitable, mais qui ne demande (qui sait ?) qu'à être contredite.

2 Celle-ci porte sur les spectacles ayant recours aux modèles télévisuels. Cela n'est pas nouveau, et il y a longtemps que des artistes se saisissent de ce vocabulaire. Pastiche d'émission de téléréalité, faux journal d'information, talk-show qui dérape, confidences intimes sur divan ou encore caricature de débat politique viennent agrémenter un propos, quand cette forme n'architecture pas carrément le spectacle. S'il serait réducteur de vouloir généraliser les motivations et choix dramaturgiques amenant les équipes à ces recours, je ne peux m'empêcher de relever la récurrence de certains traits communs ou d'intentions. Pourquoi la télé ? D'abord, il y a eu, longtemps, l'idée d'une critique de la télévision et de ce qu'elle produit - ou pas, justement en termes de pensée -, avec l'opposition théâtre (= art, culture, élévation de l'esprit, blablabla) Vs télévision (= abrutissement des masses, bouuuuh). Un schéma caricatural, assez simpliste comme si le premier intrinsèquement valait mieux que le second - qui n'a plus guère cours aujourd'hui. Pourtant oui, ce sont fondamentalement deux objets différents. A ce sujet, on reprendra la différence énoncée par le critique de cinéma Serge Daney entre cinéma et télévision, le premier relevant de la "projection», la seconde de la "diffusion ». On se projette dans le théâtre comme dans le cinéma, là où la télévision nous assène un produit fini, plein. Mais aujourd'hui, il semble suffire que le théâtre en passe par la télévision, pour que la distance critique soit là et que le premier passe pour un rempart contre le populisme du second.

3 Mais, alors, pourquoi la télé ? Que permet ce choix ? Formellement, le recours à la grammaire télévisuelle crée du commun, en exploitant des références populaires, connues et partagées par tous. Formellement toujours, cela permet d'avoir une esthétique à peu de frais, usant d'artifices aussi grossiers qu'efficaces - bah ouais, la télé n'a pas souvent fait dans la dentelle. Jeu de lumières surchargé et vulgaire, musiques de variété dégoulinantes balancées à fond, paillettes, interprétation des 
comédiens outrée: tout l'arsenal du divertissement et de l'entertainment peut être convoqué. Avec toujours l'idée que le passage au théatre par la distance qu'il instaure vaudrait comme critique de ce système et de ces rouages. Mais par ses conditions de production et d'existence, le théatre sait qu'il ne pourra jamais atteindre le mimétisme parfait. Incapable d'égaler une forme, il préfère la dépasser, la compenser par le recours à une potacherie de bon aloi ou à un cynisme affiché. En faire plus que la télé en surpassant non pas sa forme mais le jeu de références, de clins d'œil et de stéréotypes (parfois graveleux, la télé autorisant toutes les pentes, même les plus crasses) pour susciter le rire et l'adhésion des spectateurs, et en recourant à divers raccourcis de narration. [Toi, public, qui a eu le bon goût de quitter ton canapé et ton écran ce soir pour venir au théâtre, tu en auras pour ton argent.]

4 Vous me direz que certes, des spectacles utilisent la grammaire télévisuelle. Mais ils la critique, en la démontant. Alors, oui, il est vrai qu'un autre point commun de ces spectacles est le vrillage du dispositif télévisuel. Cette torsion peut passer, par exemple, par le retournement des enjeux du jeu, la bascule dans le fantastique, l'incursion de personnages mythologiques, le démontage (ou le refus) par certains protagonistes du cadre de l'émission, le glissement vers un jeu de massacres (sang, sexe, mort), etc. Mais, étrangement, cela ne change rien et ce renversement lui-même devient conformisme. Si le théâtre a alors le sentiment d'exploser la forme télévisuelle, et de produire une critique sur celle-ci, il ne fait au final que s'y enferrer.

5 Pour terminer, une citation de Serge Daney. Un extrait tiré d'une interview donnée à Arnaud Viviant, dans lequel Daney évoque sa chronique tenue dans Libération et consacrée à la télévision :

«(...) la télé, c'est l'oubli de l'écriture. Et quand l'écrit légifère sur quelque chose qui n'est pas encore du domaine de l'écriture et ne le sera peut-être jamais, il est en porte-en-faux. Ce n'est pas bien de faire le petit malin avec des objets qui ont été conçus pour être jetés. Car qu'est-ce qu'on trouve alors ? Des banalités sociologiques. On n'est même plus Barthes. Il faut aller au Japon pour comprendre ce que c'est qu'une culture qui a réussi son rapport aux objets, qui n'en fait pas toute une histoire. Là-bas, le papier pour recouvrir les livres est bien supérieur au nôtre, comme tous les objets de la vie quotidienne. Oui, mais pas de quoi en faire un discours... C'est la vulgarité même. Ce serait inefficace, parasitaire, un peu indigne, m'as-tu-vu. Comme être plus intelligent que la télé. Car la télé ne cherche pas à être intelligente. Elle est comme l'inconscient qui calcule, disait Freud, et tombe toujours juste ${ }^{1}$. »

\section{NOTES}

1. Voir l'interview au complet sur le site des Inrockuptibles: http://www.lesinrocks.com/ 1992/03/01/cinema/actualite-cinema/serge-daney-les-cahiers-a-spirales-11225636/ 
INDEX

Mots-clés : Daney (Serge), télévision 